\title{
O DELÍRIO DO PSICÓTICO COMO FENÔMENO DE LINGUAGEM
}

Walker Douglas Pincerati ${ }^{1}$

\section{RESUMO}

O dizer psicótico tem uma opacidade que lhe é própria. Consequentemente, exige uma escuta que não tome a psicose no campo da patologia, mas no da psicopatologia. A análise da construção da palavra de efeito neológico de um psicótico mostra um elaborado trabalho do pensamento. A linguagem não se mostra aí apenas como uma manifestação e auxiliar do pensamento, mas causa de haver sujeito. Ao desvelar um funcionamento da 'potência patológica da linguagem', a construção delirante do efeito neológico, de fato, deixa entrever um modo outro do psicótico habitar a linguagem.

Palavras-chave: Distúrbio de linguagem. Efeito neológico. Psicopatologia. Dizer psicótico.

\section{INTRODUÇÃO À INDAGAÇÃO SOBRE OS DISTÚRBIOS DA LINGUAGEM}

A coação que sofremos quando interrogamos o divergente, 0 insólito e 0 heterogêneo que se atualiza, seja na fala da criança e do afásico, seja no dizer psicótico suscita, de fato, questões complexas. Penso que, em se tratando da linguagem em contextos tidos patológicos, a questão primeira a ser levantada é a de saber o que e que fundamentos permitem definir precisamente o que é e o que não é um distúrbio. É, portanto, necessário que comecemos a delimitar os campos.

Aqui $^{2}$, o enfretamento dessa questão se inscrever efetivamente na delicada discussão dos limites do novo campo de estudos chamado Linguística e Psicanálise, que tem se constituído dentro da Universidade desde a década 1990 e congrega, de maneira geral, linguistas, psicanalistas, fonoaudiólogos e psicólogos ${ }^{3}$. 
Confesso que prefiro denominar esse campo de Estudos da Linguagem e Psicanálise ou, apenas, Linguagem e Psicanálise, visto que a Linguística, embora compareça nos estudos da linguagem, se ocupa da língua.

O foco aqui está voltado aos distúrbios da linguagem ou, mais propriamente, às alterações da linguagem que se atualizam nos dizeres na psicose, destacando sua diferença em relação aos dizeres nas patologias; no caso, as afasias.

Como os próprios psiquiatras afirmam (ver, por exemplo, VANIER, 2010), poucos são aqueles que ainda escutam sem censura (cf. FOUCAULT 1971) os dizeres nas patologias e nas psicopatologias. $E$ é isso que tem levado a uma obliteração - que os psiquiatras (cf. BIRMAN, 2001; COUDURIER, 2005; PEREIRA, 2002, 2013; QUINET, 2001a, 2001b; SERPA JR., 2001) entendem ser a causa de uma "crise da psiquiatria" - ou confusão dos modos distintos do sujeito sofrer e, consequência disso, provocado um apagamento das diferenças clínicas e da própria clínica.

De fato, embora se tenha como objetivo discutir a noção de 'escuta', não perdendo de vista as questões complexas impostas quando se aproxima linguística e clínica, minha pesquisa, em relação às realizadas no campo das patologias, apresenta uma importante diferença. Ora, a Clínica da Linguagem, que se constitui no âmbito dos campos de estudos aqui em questão (mais a Fonoaudiologia), é interrogada pelas falas da criança e, sobretudo, os dizeres nas patologias (cf. LIERDEVITTO, 2006). A psicose é uma psicopatologia. Portanto, interroga a clínica psiquiátrica e a psicanalítica a respeito da natureza daquilo que afeta e que faz sofrer o psicótico; e que os psiquiatras entendiam se tratar de uma afecção que tem origem numa "lesão psíquica". Ou seja, entendiam que algo aconteceu com o sujeito de tal modo que perturbou sua relação com o mundo (cf. FOUCAULT, 2003).

\section{DA DIFERENÇA ENTRE PATOLOGIA E PSICOPATOLOGIA DA LINGUAGEM}

Enquanto estudioso da linguagem na psicose, minha proposta, obviamente, difere da dos psiquiatras. Ela consiste em dizer que, na psicopatologia, algo aconteceu na linguagem de tal modo que a relação do falante com ela ficou perturbada. Trata-se, portanto, de dar primazia aos efeitos da linguagem no ser falante. O médico, pelo contrário, dá primazia à lesão e sua pesquisa clínica está centrada na noção de 'déficit'. Isso, contudo, não significa ignorar o que ele faz. 
Porém, não significa igualmente se submeter ao discurso médico (cf. NOVAES, 1996). Em outras palavras, meu interesse pela clínica está pautado não no déficit físico ou psíquico, mas nos efeitos que esse acontecimento tem e produz no corpo do falante enquanto um habitante da linguagem. É por essa razão que a Psicanálise serve aos meus propósitos.

Sabe-se que o psiquiatra Jacques Lacan foi levado à Psicanálise devido a suas questões sobre a clínica das psicoses. Mais conhecido ainda é o fato de que, nessa trajetória, ele passou pela Linguística de Saussure e Jakobson. Essa passagem teve, certamente, grandes consequências para todo o movimento psicanalítico (e, também, disciplinas correlacionadas). Afinal, o projeto de Lacan era mostrar que a linguagem é a morada do ser humano, visto que ele se constituiu como tal em sua trajetória na linguagem que o levou da condição de infans à de sujeito falante ${ }^{4}$. A partir de então, não há mais volta: não haverá, faltamente, para ele nada fora da linguagem (cf. LACAN, 2009, p. 114).

A propósito, é isso que faz Lacan se distanciar da Psiquiatria e da Psicologia. Se, diz ele em clara referência à psicologia científica, o psicológico é o etológico, isto é, "o conjunto dos comportamentos do indivíduo, biologicamente falando, nas suas relações com seu meio natural”, então a Psicanálise não é psicogênese (LACAN, 2009, p. 16). Em matéria de psicologia humana é preciso ir mais além:

Da psicologia humana, é preciso dizer o que dizia Voltaire da
história natural, a saber: que ela não é tão natural assim, e, em
resumo, que ela é o que há de mais antinatural. Tudo o que, no
comportamento humano, é da ordem psicológica está
submetido a anomalias tão profundas, apresenta a todo
instante paradoxos tão evidentes, que surge o problema de
saber o que é preciso nela introduzir para que a gata encontre
seus filhotes. (LACAN, 2009, p. 16).

O diálogo que Lacan estabelece com a Linguística, a Antropologia e, entre outros campos de saber, com a Filosofia e as Artes visa introduzir o humano no campo que o define como tal: a linguagem. Segundo Melman (2009), o reconhecimento de Lacan de que o humano está alienado à linguagem, faz com que ele ultrapasse a querela, a seu ver, estéril entre partidários da organogênese e da psicogênese:

Consideremos um mérito primordial de Jacques Lacan a ultrapassagem dessa querela estéril com o isolamento (enfim!) 
da organização material da qual é tributária a especificidade psíquica do sujeito humano: a do significante.

É preciso dar a essa asserção todo o seu peso: ela impõe a existência de uma estrutura cujas propriedades e fisiologia sobrepõem suas leis e sua topologia à mecânica do organismo e a desnaturam em uma psique; essa estrutura é a da linguagem. (MELMAN, 2009, p. 19).

Note-se que, em Lacan, não há uma separação entre sujeito e linguagem. O sujeito, pelo contrário, é efeito de linguagem. Ou ainda, a linguagem é causa de haver sujeito: "Eu insisto - a ordem simbólica deve ser concebida como alguma coisa de superposto, e sem o que não haveria vida animal possível para esse sujeito estrambótico que é o homem." (LACAN, 2009, p. 114)

A linguagem é, portanto, o que nos diferencia dos outros animais porque 0 homem sabe que há morte e é assombrado por isso. Pior, ele sabe que essa tragédia é certa, mesmo que não datada.

Ora, a "afasia universal" ${ }^{5}$, concebida teoricamente por Jakobson (2003, p. 60), não significaria justamente a efetivação dessa tragédia? Não é contra isso que os afásicos lutam, mesmo quando se agarram a um fragmento ou "resto de linguagem"? O sucesso da clínica das afasias não é, justamente, encontrado quando o clínico, emprestando sua escuta à fala afásica, pesquisa com o afásico o modo de ele mesmo reencontrar sua própria fala, atenuando assim sua angústia? Com efeito, a noção de 'escuta' é central na Clínica da Linguagem.

Porém, as dificuldades dessa Clínica são de outra natureza, pois suas questões estão centradas nos efeitos de linguagem face aos efeitos da lesão. Nela, linguagem e lesão são estruturas heterogêneas e a dificuldade está em compreender a complexidade do fenômeno que se produz, a partir da dialética dos efeitos dos acontecimentos nessas duas estruturas.

Na psicose, é a própria alteridade da linguagem que comparece em sua face mortal e invasora. Isto é, num dado momento, uma face heterogênea da própria linguagem se desnuda ao sujeito e, a partir de então, ele escuta uma voz que fala coisas horríveis dele para ele, como se fosse um terceiro que falasse com ele. Aqui, note-se bem, é a própria linguagem que se altera e é a causa do sofrimento; é ela que se comporta como se fosse uma lesão ou agente patogênico. Essa é a diferença entre patologia e psicopatologia.

A Psicopatologia, enquanto disciplina psiquiátrica, quer saber quais são os efeitos mortais da linguagem no corpo para edificar sua clínica e terapêutica. Por 
sua vez, o estudioso da linguagem nas psicopatologias quer saber que propriedades tem a linguagem que possibilitam tal conflito, isto é, como a linguagem produz tal heterogeneidade em relação a si mesma. $E$, ainda, por que a linguagem, que é a morada do homem, em determinadas psicopatologias produz tanto sofrimento e horror, como é o caso da psicose. O objeto de estudos que se delineia é a dimensão ou "potência patológica da linguagem", tal como nomeou Deleuze (2009, p. 47). Afinal, que leis de funcionamento da própria linguagem possibilitam a produção dessa potência?

Se há na psicose uma dimensão da linguagem que comparece como terceira, cuja propriedade tem o poder de causar sofrimento, então o que se apresenta a nós como um distúrbio de percepção constitui uma armadilha, visto que as vozes ou o que é alucinado de fato não existem lá fora. A armadilha consiste em acreditar que não se trata mais de linguagem. Desse modo, um grande problema se coloca: que escuta emprestar à fala do psicótico de maneira que se possa descrever, analisar e compreender essa 'dimensão patológica da linguagem', sem, contudo, cair na armadilha que ela produz?

A meu ver, devemos tratar esse fenômeno como uma percepção de uma face real da linguagem com linguagem. Isto é, como uma linguagem que articula algo que é impossível ou intolerável ao psicótico, de tal modo que ele tenha que escutá-lo como vindo de fora, efetivamente como exterior. Nós, neuróticos, mantemos o que nos toca e dói como um segredo. Certamente, isso determina modos distintos de estruturação do discurso na neurose e na psicose. A pesquisa, então, começa com o reconhecimento de que a linguagem na psicose apresenta uma opacidade própria, isto é, uma estrutura diferente da nossa, neuróticos.

A descoberta de que todos somos neuróticos foi feita por Sigmund Freud, no início do século 20 , nos ensaios sobre os sonhos, os chistes e a psicopatologia da vida cotidiana. É, porém, no texto A negativa (Die Verneinung), de 1925, que apresenta uma reflexão que permite avançar no entendimento da tese de que existe uma diferença estrutural entre a neurose e a psicose.

Nesse texto, discorre acerca do estatuto da negação no discurso como elucidativo do mecanismo psíquico específico da neurose. Logo de início, destaca a particularidade do modo como o paciente apresenta ao analista determinadas ideias que lhe assaltam ao longo da sessão, quando ele diz: "Agora o sr. deve estar pensando que eu queria dizer algo ofensivo, mas realmente não é essa minha 
intenção." (FREUD, 2010c, p. 147.) A negação do paciente, diz Freud, é uma maneira de ele, por projeção, repelir a ideia que acaba de aflorar em sua consciência. Disso resulta que o recalcado inconsciente pode penetrar na consciência desde que seja sob a forma negativa. Então, conclui, a negação é uma forma de tomar conhecimento do recalcado em um plano apenas intelectual, deixando o essencial do recalque intocado (cf. FREUD, 2010c, p. 48). "A atitude de condenar algo nada mais é do que um substituto intelectual do recalque e o "não" é sua marca, um certificado de origem, como se fosse um "made in Germany"." (FREUD, 2010c).

Resumidamente, o símbolo da negação desvela uma afirmação anterior (Bejahung): o eu do sujeito só pode negar algo que entrou para o campo simbólico e se constituiu como uma realidade para ele. Ou seja, "a análise do mecanismo de defesa da Verneinung (a negação) lança luz sobre o fato de que o recalcado inconsciente já pertence ao universo simbólico do sujeito: é pelo fato de que isso existe que isso pode aparecer sob a forma de negação no discurso." (APARícIO, 1984, p. 91; ênfase da autora e tradução minha).

O mecanismo específico da neurose é, pois, o recalque, que, dentre outras formas de manifestar seus efeitos, se desvela na negação de uma representação que repentinamente aflora na consciência. $O$ eu do sujeito, que é a instância psíquica em que tem curso e lugar as defesas e resistências, se protege, afastando essa representação da consciência. O sintoma é efeito da tentativa de sufocar e desalojar uma representação inconciliável e/ou reprovável da consciência, mas cujo logro não foi exitoso (cf. FREUD, 2008a, 2008b). A essência do sintoma reside no fato de que o recalcado conserva seus efeitos. Os distúrbios de linguagem dos neuróticos, ou seja, as neuroses são, assim, consequências do processo de recalque (Verdrängung).

O conceito de 'recalque', contudo, não diz nada da especificidade da psicose, porque a alucinação não especifica um juízo sobre a existência de algo a ser negado, mas sim de algo que comparece como se jamais tivesse existido. Foi Lacan quem fez do termo Verwerfung (até então traduzido por amputação, rejeição ou supressão), em Freud sem um peso conceitual definido, um conceito na teoria psicanalítica, traduzindo-o por foraclusão (forclusion) para especificar o mecanismo psíquico específico da psicose. (cf.: APARICIO, 1984; RABINOVICH, 2001; ESCARS, 1970). 
Resumidamente, em um dado momento, o sujeito é tomado por uma questão que toca a essência de ser no mundo, mas lhe falta um significante de base para fazer face a ela e os modelos até então existentes não the servem mais. Tal evocação instaura um buraco no campo da significação. Nada, nem um significante vem em suplência. Então, sem resposta, ocorre, uma elisão no simbólico. "Lacan dirá: foraclusão, isto é, ausência de Bejahung [afirmação] incidindo sobre um significante e podendo permitir, em seguida, um recalque por Verneinung [negação]." (JULIEN, 1999, p. 29.) Ou seja, o que responde é uma voz aterradora e invasiva, a alucinação. É em razão disso que o termo 'foraclusão' dá nome a uma exclusão primordial de um significante de base, referido à instância da lei paterna (que pode ser entendida, nesse momento do ensino de Lacan, como a lei da articulação significante comandada por uma significação primordial) no processo de estruturação do infans em sujeito falante; exclusão que tem por efeito uma estrutura psicótica.

O delírio, concordam psiquiatras e psicanalistas, é um fenômeno secundário, isto é, um fenômeno posterior à catástrofe interior decorrente da falta de resposta. Ele visa reconstruir o mundo do psicótico que desabou (FREUD, 2010a, p. 65-66), servindo-Ihe como habitat. Contudo, diferentemente dos psiquiatras, a psicanálise entende que a materialidade significante é constitutiva do pensamento (cf. FREUD, 2010a; 2010b, p. 46).

\title{
3 O EFEITO NEOLÓGICO NA RECONSTRUÇÃO DELIRANTE
}

Em trabalho recente (Pincerati, 2012), pude verificar isso analisando as palavras que têm efeito neológico de um psicótico, LC, cujo diagnóstico psiquiátrico é o de esquizofrenia ${ }^{6}$. Vejamos um trecho ilustrativo, em que ele conta à entrevistadora o que é necessário aplicar no corpo do pai dele para que seja igual ao dele:

\author{
LC: Eu sei que precisava ser descarga elétrica, né? \\ Entrv.: Descarga elétrica? \\ LC: Uma onda de columb. \\ Entrv.: De quê? \\ LC: Columb. Raios Columb, energia Columb. Beta, beta ômega alfásica, \\ beta, alfa e ômega. Tem que aplicar isso no corpo dele.
}

(PINCERATI, 2012, p. 81-82. Grifos meus). 
A palavra de efeito neológico alfásica é, sem dúvida, estranha. Mas é possível reconhecê-la como uma forma possível na língua portuguesa, embora não a reconheçamos como atualizada. Por essa razão, ela não constitui um neologismo, se entendermos como tal a unidade lexical nova que surge na fala e que é passível de entrar na língua e circular no discurso ordinário.

Se atentarmos, contudo, para o fato de que o tema do delírio dele é a eletricidade e que, para LC, ela serve a um propósito superior, qual seja, que seu corpo é especial e que é animado por eletricidade, entrevemos a razão da construção de tal significante: alfásica não só é um substantivo erudito formado pela composição dos substantivos alfa + fásica, que, por sua vez, é derivação de fase com o sufixo nominal formador de substantivos eruditos, -ica. Há, além disso, um trabalho do pensamento no trabalho dos significantes: a partir do momento em que descarga elétrica é dito, uma constelação de significantes igualmente concernidos à eletrônica se atualizam no dizer, como se fosse um efeito em cascata. No último trecho da fala de LC, escutamos perfeitamente um bloco maciço de elementos eletromagnéticos que cada vez mais se especificam: de raios e energia, passa para formas mais elementares dessa energia ou raios, beta, ômega e alfa. É assim que LC concebe um corpo especial: alfásica condensa uma corrente de pensamento que trabalha o corpo enquanto máquina, e o sangue, enquanto energia ou corrente elétrica.

Alfásica é, pois, plena de significação, mesmo que essa significação não seja dialetizável: ela encapsula em sua forma todas as representações e propósitos superiores do delirante. Disso resulta que, embora insólita, atenua a angústia do psicótico na mesma medida em que dá um lugar todo especial a ele no mundo. $O$ efeito neológico denuncia esse processo.

\section{BREVES PALAVRAS PARA (NÃO) CONCLUIR}

Essa análise, com efeito, impõe a necessidade de melhor compreender o delírio enquanto um fenômeno de linguagem, uma vez que ele emerge como resposta aos fenômenos que invadem repentinamente o sujeito na eclosão de sua psicose. Ou seja, é preciso saber quais elementos o delírio atualiza, que leis de funcionamento da linguagem estão em causa na estruturação dele como um 
discurso e que análise permite melhor dizer sobre a dimensão e a potência patológica da linguagem.

\title{
NOTAS
}

1 Bacharel, Mestre e Doutorando em Linguística no DL/IEL/Unicamp (bolsa CNPq); pesquisador associado do Centro de Pesquisa Outrarte: estudos entre psicanálise e arte (IEL/Unicamp).

${ }^{2}$ Esta é uma versão ampliada do trabalho apresentado no dia 06 de junho de 2011 na Sessão Coordenada "Crianças, afásicos e psicóticos: falas e dizeres que interrogam a Clínica da Linguagem", que teve lugar no XVI Congresso Internacional da Associação Latinoamericano de Linguística e Filologia da América Latina (ALFAL), em Alcalá de Henares, Espanha.

${ }^{3}$ Tenho, sobretudo, em mente os trabalhos coordenados por Nina Leite, no projeto Semasoma, e os desdobramentos daqueles, em Aquisição da Linguagem, levados a cabo por Cláudia Lemos; ambas no Instituto de Estudos da Linguagem da Universidade Estadual de Campinas, IEL/Unicamp. Os esforços e frutos deles levaram à criação do centro Outrarte: estudos entre psicanálise e arte, que congrega estudiosos de várias universidades.

${ }^{4}$ A linguagem na psiquiatria médica não passa de uma faculdade anatômica e fisiologicamente localizada e auxiliar do pensamento cuja manifestação se dá pela fala. A fala é, pois, apenas uma ação que permite manifestar o pensamento, que, quando normal, dá a ver uma linguagem organizada e razoável. $\mathrm{Na}$ linguística científica, grosso modo, ela é uma junção entre fala e língua. A Psicolinguística e a Neurolinguística, então, visam teorizar e descrever a gramática dessa faculdade de linguagem atualizada objetivamente na fala. Todo o trabalho de Cláudia Lemos põe, justamente, em questão essa transparência postulada, uma vez que os corpora constituídos por falas de crianças não se prestam à pura descrição dessa faculdade em desenvolvimento (cf. De Lemos 2006). Pelo contrário, deixam entrever mudanças de posição da criança em uma estrutura cujos dois pólos são o outro e a língua.

${ }^{5}$ A afasia universal é concebida teoricamente em Jakobson como resultado de uma lesão que produziria ao mesmo tempo tanto uma afasia sensorial como uma afasia motora extremamente severas que aboliriam a linguagem no indivíduo. A meu ver, levando em consideração a importância do texto de Jakobson para os estudos da linguagem, esse tipo de afasia representa a abolição da condição de falante de um sujeito, o que representa a morte contra a qual ele luta.

${ }^{6}$ As entrevistas com LC foram realizadas por Fernanda D. Picardi, que, em 1997, defendeu a dissertação Linguagem e Esquizofrenia: na fronteira do sentido no IEL/Unicamp sob a orientação da $\operatorname{Prof}^{a} \operatorname{Dr}^{a}$ Nina Leite. Picardi disponibilizou a transcrição das entrevistas no Apêndice da dissertação. Elas foram realizadas no Serviço de Saúde "Dr. Cândido Ferreira", Campinas/SP. Na época, LC era um paciente semi-interno, tinha 29 anos e seu diagnóstico psiquiátrico era de esquizofrenia.

\section{PSYCHOTIC DELUSION AS LANGUAGE PHENOMENON}

\author{
ABSTRACT \\ Psychotic speech is opaque in its own terms. It therefore demands a listening that \\ posits psychosis in the field of psychopathology instead of pathology. The analysis of \\ the construction of the psychotic's words of neologic effect displays a complex work
}


of thought. Language does not surface as mere manifestation, as a tool of thought, but rather as a cause for the emergence of a subject. By unveiling how the "pathological power of language" works, the delirious construction of the neologic effect lets us picture another mode in which the psychotic inhabits language.

Keywords: Language disorder. Neologic effect. Psychopathology. Psychotic speech.

\section{REFERÊNCIAS}

APARICIO, Sol. La forclusion, préhistoire d'un concept. Ornicar?. Paris, v. 28, p. 83105,1984 .

BIRMAN, Joel. Despossessão, saber e loucura: sobre as relações entre psicanálise e psiquiatria hoje. In: QUINET, Antonio (Org.). Psicanálise e psiquiatria: controvérsias e convergências. Rio de Janeiro: Rios Ambiciosos, 2001.

COUDURIER, Jean-François. À propos du DSM. Essaim, Paris, v. 15, p. 21-33, 2005.

DE LEMOS, Cláudia T. G. Uma crítica (radical) a noção de desenvolvimento em aquisição de linguagem. In: LIER-DEVITTO, Maria Francisca (Org.). Aquisição, patologias e clínica de linguagem. São Paulo: EDUC, 2006.

DELEUZE, Gilles. (1968) Diferença e repetição. São Paulo: Graal, 2009.

ESCARS, Carlos. O homem dos diagnósticos, da história de um dilema lacaniano. Psicoses, Escola Letra Freudiana, Goiânia, v. 36, p. 121-142, 1970.

FOUCAULT, Michel. (1961) História da loucura na idade clássica. São Paulo: Perspectiva, 2003.

. L'ordre du discours: leçon inaugurale ao Collège de France prononcée le 2 décembre 1970. Gallimard: Paris, 1971.

FREUD, Sigmund. (1894) Las neuropsicosis de defensa (ensayo de una teoría psicológica de la histeria adquirida, de muchas fobias y representaciones obsesivas, y de ciertas psicosis alucinatorias). In: Amorrortu, 2008a. . Obras completas, v. 3. Buenos Aires:

. (1896) Nuevas puntualizaciones sobre las neuropsicosis de defensa. In: . Obras completas, v. 3. Buenos Aires: Amorrortu, 2008b.

. (1911) Observações psicanalíticas sobre um caso de paranóia (Dementia paranoides) relatado em autobiografia ("O caso Schreber"). In: Obras completas, v. 10. São Paulo: Companhia das Letras, 2010a. 
. (1915) O inconsciente. In:

inconsciente, v. 2. Rio de Janeiro: Imago, 2010b.

. Escritos sobre a psicologia do

. (1925) A perda de realidade na neurose e psicose. In: . Escritos

sobre a psicologia do inconsciente, $v$. 3. Rio de Janeiro: Imago, 2010c.

JAKOBSON, Roman. (1956) Deux aspects du langage et deux types d'aphasies. In : Essais de linguistique générale 1 : les fondations du langage. Trad. Nicolas Ruwet. Paris: Minuit, 2003.

JULIEN, Philippe. As psicoses: um estudo sobre a paranóia comum. Rio de Janeiro: Companhia de Freud, 1999.

LACAN, Jacques. (1955-56) O seminário: livro 3: as psicoses. Texto estabelecido por Jacques-Alain Miller. Rio de Janeiro: Jorge Zahar, 2009.

LIER-DEVITTO, Maria. Francisca. (Org.). Aquisição, patologias e clínica de linguagem. São Paulo: EDUC, 2006.

MELMAN, Charles. Contribuição da psicanálise à semiologia psiquiátrica. Com comentários de Jacques Lacan. In: CZERMAK, M.; JESUÍNO, Â. (Orgs.).

Fenômenos elementares e automatismo mental. Rio de Janeiro: Tempo Freudiano, 2009.

NOVAES, Mariluci. Os dizeres nas esquizofrenias: uma cartola sem fundo. São Paulo: Escuta, 1966.

PEREIRA, Mário Eduardo Costa. O futuro da psicanálise. In: ALONSO, A.; ARAÚJO, R. (Orgs.). O futuro da psicanálise. Rio de Janeiro: Rios Ambiciosos, 2002

. O DSM e a crise da psiquiatria. CULT. O poder da psiquiatria: o que está por trás da psiquiatrização da vida cotidiana, n. 184, p. 38-45, out./2013.

PINCERATI, Walker. A loucura das palavras na psicose. Campinas: Mercado de Letras, 2012.

QUINET, Antonio. Apresentação. In: QUINET, Antonio (Org.). Psicanálise e psiquiatria: controvérsias e convergências. Rio de Janeiro: Rios Ambiciosos, 2001 a. p. 7-10.

. A psiquiatria e sua ciência nos discursos da contemporaneidade. In: QUINET, Antonio (Org.). Psicanálise e psiquiatria: controvérsias e convergências. Rio de Janeiro: Rios Ambiciosos, 2001b.

RABINOVICH, Solal. A foraclusão: presos do lado de fora. Rio de Janeiro: Jorge Zahar, 2001.

SERPA JR., Octavio Domont de. Psicanálise, psiquiatria e a sedução da completude. In: QUINET, Antonio (Org.). Psicanálise e psiquiatria: controvérsias e convergências. Rio de Janeiro: Rios Ambiciosos, 2001. 
STAGNARO, Juan Carlos. Presentación. In: KRAEPELIN, Emil. Demencia precoz. Buenos Aires: Polemos, 2008.

VANIER, Alain. 2010. Une introduction à la psychanalyse. Paris: Armand Colin. 